\title{
EL ACOMPAÑAMIENTO ESPIRITUAL EN LA VIDA DEL SACERDOTE
}

DOI: https://doi.org/10.52039/seminarios.v63i220.75

FERNANDO VALERA SÁNCHEZ*

Es sorprendente que la nueva Ratio fundamentalis instituionis sacerdotalis ${ }^{1}$, presenta el discernimiento y el acompañamiento espiritual del candidato al sacerdocio como medio de formación en el marco de la identidad propia del sacerdocio. En este sentido, la vida del presbítero es la que queda implicada en el ministerio, quedando asumida y marcada. Toca a la profundidad personal y a la totalidad del ser. Esta «totalidad» es también un «para siempre», un ejercicio de por vida.

La dinámica del Espíritu es connatural a la vida del presbítero2: llegar a ser «adulto en Cristo» (Ef 4, 3), combatir como «buen soldado de Cristo» (2 Tim 2, 3), «caminar de manera digna de la vocación recibida» (Ef $4,1)$, para ser fiel a la invitación del apóstol: «Reaviva el carisma de Dios que está en ti» (2 Tim 1, 6): «Los presbíteros, configurados en su ser con Cristo Cabeza, Pastor, Siervo y Esposo, participan de su único sacerdocio y de su misión salvífica como colaboradores de los obispos. Así son en la Iglesia y en el mundo un signo visible del amor misericordioso del Padre» (Ratio 35).

Quisiera definir el acompañamiento espiritual «como la ayuda dada por un creyente a otro que le permite prestar atención a lo que Dios le comunica, responder a ese Dios que se comunica personalmente, crecer en intimidad con él y vivir las consecuencias de esta relación» ${ }^{3}$. Por esta

* Sacerdote diocesano de Cartagena-Murcia. Es Director espiritual del Seminario de San Fulgencio y profesor en el Instituto Teológico San Fulgencio de dicha diócesis.

1. Congregación para el Clero, El don de la vocación presbiteral. Ratio fundamentalis institutionis sacerdotalis, 2016.

2. La dimensión pneumatológica del discernimiento y la dirección espiritual en el presente trabajo será muy importante, cf. F. Valera Sánchez, El Espíritu Santo y la vida del presbítero. Estudio teológico, empírico y sistemático de la espiritualidad presbiteral a partir de "Pastores dabo vobis», UCAM, Murcia 2002, 223-244. 27-28.

3. W. A. Barry - W. J. Connolly, La práctica de la dirección espiritual, Santander 2011, 
misma razón, el lugar primero y fundamental es el espacio donde el presbítero es lo más verdadero en sí mismo, como acción propia del Espíritu Santo. La verdad más profunda de su ser: «Espiritual, nos indica que el interés fundamental de este tipo de ayuda no está en las acciones externas como tales, sino en la vida interior, en el corazón..., y nos recuerda también que hay otro Espíritu implicado: el Espíritu de Dios. Dirección sugiere algo más que dar consejos y resolver problemas. Significa que la persona que busca dirección se dirige a alguna parte y quiere hablar a alguien mientras camina» ${ }^{4}$.

Por tanto, nuestra primera tarea es intentar entender algunos aspectos del contexto cultural y religioso en el que nos movemos en el acompañamiento espiritual.

\section{1. «UNA CIVILIZACIÓN HERIDA DE ANONIMATO» ${ }^{5}$}

En Evangelii gaudium, el papa Francisco nos presenta un itinerario de acompañamiento espiritual que parte de la siguiente afirmación: «En una civilización paradójicamente herida de anonimato y a la vez obsesionada por los detalles de la vida de los demás, impudorosamente enferma de curiosidad malsana, la Iglesia necesita de una mirada cercana para contemplar, conmoverse y detenerse ante el otro cuantas veces sea necesario. En este mundo los ministros ordenados y los demás agentes pastorales pueden hacer presente la fragancia de la presencia cercana de Jesús y su mirada personal $»^{6}$.

La respuesta a este anonimato malsano es profundizar en la propia identidad. Así, obrar continuamente como pastor a través de la multiplicidad de tareas proféticas, sacramentales y de gobierno va configurando en el espíritu del presbítero la silueta del pastor, que actúa en representación de Jesucristo Buen Pastor. De ese modo, el hacer va alimentando el ser, llenando de profundidad y autenticidad en su ejercicio lo que se es gracias al Espíritu Santo. El ministerio se convierte en carisma de totalidad ${ }^{7}$.

4. Ibid., 31.

5. Francisco, Evangelii gaudium, 169.

6. Ibid., 169.

7. «Un ministerio tan vital para la comunidad no puede sino tocar en vivo a la persona del ministro, no sólo en su conducta externa, sino en su vivencia interior; afecta el centro mismo de la persona del ministro. El presbítero queda reclamado por esta instancia ministerial que afecta a su vida y se constituye en la fuente genuina de su propia espiritualidad. El ministerio es, por ello, carisma de totalidad» (S. Gamarra, Espiritualidad del sacerdote, Surge 49 [1991] 212). 
Por la entrega del Espíritu al Padre por parte de Jesús en la cruz, se infunde en toda carne el Espíritu de unidad y de paz. Es el Espíritu que clama: «¡Abba!, ¡Padre!» (Gal 4, 7; Rm 8, 15), haciéndoles hijos en el Hijo, reconciliándoles con Dios y entre ellos en su amor crucificado. Es el Espíritu del bautismo, de la confirmación y de la ordenación quien convierte el pan y el vino en cuerpo y sangre de Cristo, el que hace participar al sacerdote de la misión de Cristo y de la Iglesia. El Espíritu hace que quien lo acoge pueda decir con Pablo: "Ya no vivo yo, vive Cristo en mí» (Gal 2, 20). La Iglesia es el Cuerpo de Cristo por ser Templo del Espíritu, comunidad de la alianza eterna que es el Señor Jesús en persona, vivificado y vivificante por el Espíritu. Por ello hemos señalado que el Espíritu es el «éxtasis de Dios», aquel que hace capaz la salida de Dios de sí mismo, su apertura al otro. Esta concepción se confirma en el hecho de que, cada vez que a lo largo de la historia de la salvación el Eterno se expresa «ad extra», lo hace en el Espíritu. Y el orden sacerdotal es expresión de esta manifestación, como lo fue el Espíritu cuando se movía sobre las aguas de la primera creación, cuando se posó sobre los profetas, cuando cubrió a la Virgen María, cuando ungió al Verbo encarnado y cuando descendió en Pentecostés para constituir la Iglesia de los discípulos unidos en el amor. El Espíritu, por tanto, es el principio de la unidad, que supera divisiones y diferencias, de paz en los corazones uniéndolos en la alegría de la comunión con el Padre y con el Hijo, es el alma de la unidad de la Iglesia y hace de esta unidad signo, instrumento y profecía de la unidad del mundo. Pero el Espíritu es también quien consuma la unidad interior, quien une las diferencias, quien en la poliédrica expresión de la vida humana y del ministerio presbiteral da unidad en el amor.

Esta unidad de vida se hace difícil en el nuevo contexto cultural. Esta aporía socio-cultural sólo es posible superarla desde una antropología que tenga en cuenta la relación subjetividad/exterioridad como indicaciones de un mismo discurso. La subjetividad se convierte en vía de acceso a la transcendencia por la interpelación del «rostro del otro» ${ }^{8}$, pero también por una antropología transcendental que tiene en cuenta que si Dios quiere salir de sí mismo libremente, debe crear al hombre capaz de recibirle a su vez libremente. El hombre unificado es el hombre «nómada», que corta un día rompiendo todo cordón umbilical que le ata y parte hacia la

8. «La transcendencia del rostro es, a la vez, su ausencia de este mundo en el que entra, el destierro de un ser, su condición de extranjero, de despojado, de proletario... Esa mirada que suplica y exige... privada de todo» (E. Levinas, Totalidad e infinito, Sígueme, Salamanca 1977, 77, 108). 
tierra sin retorno, hacia la noche sin crepúsculo, con una sola esperanza: llegar a la tierra nueva donde habita el Espíritu de Dios, Espíritu de vida, Espíritu de Amor.

El sacerdote, unificado por dentro en un contexto de fragmentación y de «parciales sentidos», en un mundo donde faltan grandes utopías humanistas, hace que aparezca universalmente válido el horizonte subjetivista donde en la práctica todo se traduce en «mis propias valoraciones», tanto racionales, éticas, de felicidad, de la Iglesia, etc. Incluso la misma experiencia de Dios, frente a cualquier interpretación objetivadora, sea de la Revelación, sea del Magisterio o de cualquier otra instancia, se hace difícil. Es la tentación del subjetivismo que tiende a instalarse en el presbítero y que sufre, por tanto, una tentación de fragmentación interior en el nivel más profundamente personal ${ }^{9}$. Es una situación «laberíntica», ya que en nada ayuda a encontrar sentido humano; es una especie de océano de sensaciones que tienden a inscribir en el interior del hombre un «hombre záping» que le hace un receptor fragmentario e inconexo de la realidad ${ }^{10}$.

\section{2. «MIRADA CERCANA PARA CONTEMPLAR, CONMOVERSE Y DETENERSE» ${ }^{11}$}

La exhortación de Juan Pablo II Pastores dabo vobis presenta el camino de la vida espiritual del presbítero como fruto del amor, que se concreta en la caridad pastoral: "La caridad pastoral constituye el principio interior y dinámico capaz de unificar las múltiples y diversas actividades del sacerdote. Gracias a ella puede encontrar respuesta la exigencia esencial y permanente de unidad entre la vida interior y tantas tareas y responsabilidades del ministerio, exigencia tanto más urgente en un contexto sociocultural y eclesial fuertemente marcado por la complejidad, la fragmentación y la dispersión. Solamente la concentración de cada instante y de cada gesto en torno a la opción fundamental y determinante de «dar la vida por la grey» puede garantizar esta unidad vital, indispensable para la armonía y el equilibrio espiritual del sacerdote» (PDV 23).

9. Cf. J. M. Rovira Belloso, Situación socio-cultural y espiritualidad de los sacerdotes, en Comisión Episcopal del Clero, Espiritualidad sacerdotal, Congreso, Madrid 1989, 5-33.

10. «De esta manera el universo se le presenta no como un cosmos, sino como una colección de sonidos, colores, sabores que no puede sintetizar y ni siquiera lo pretende. Poéticamente lo expresaba Marguerite Youcernar en sus cuentos orientales: «El mundo no es más que un amasijo de manchas confusas, lanzadas al vacío por un pintor insensato, borradas sin cesar por nuestras lágrimas» (P. Algárate, El laberinto como paradigma, Estudios trinitarios 32 [1998] 97-113).

11. Francisco, Evangelii gaudium, 169. 
Por su parte, el papa Francisco plantea que esta caridad pastoral es «una mirada cercana para contemplar, conmoverse y detenerse ante el otro cuantas veces sea necesario» ${ }^{12}$.

El Espíritu que en el amor unifica y expresa el amor del Padre y del Hijo construye la unidad interior del presbítero. Todo en la vida del presbítero está ligado entre sí por un objetivo: dar la vida. El Espíritu de Dios, ardiente y eficaz, es el que unifica la vida, no las cosas que se hacen ni tampoco el "oficio» que se realiza. Es la experiencia de un gran amor que posibilita la síntesis y facilita la integración. Es la nueva sabiduría del corazón, hecha de acogida y armonía, de compasión y delicadeza, de comunión y participación con toda la realidad personal e interpersonal que Dios pone en el camino.

Donde un presbítero se trasciende, y trascendiéndose suscita gratuidad y creación en su existencia, allí se transparenta el Espíritu divino. Se transparenta en aquella comunión donde la herencia de Jesús se hace presente, se proclama la Palabra, se rememora su entrega en el Cuerpo y en la Sangre y en la caridad pastoral. Tal es el sentido del verdadero icono del Espíritu, que todo lo lleva a la unidad en el amor que se proyecta y suscita camino de realización del Reino; creatividad como surgimiento de nuevas posibilidades de anuncio; llamada a transcender allí donde uno se pierde y, perdiéndose, se gana.

El Espíritu del Señor concede «el ritmo sanador de projimidad, con una mirada respetuosa y llena de compasión, pero que al mismo tiempo sane, libere y aliente a madurar en la vida cristiana» ${ }^{13}$. Esto supone confianza y gozosa seguridad. El Espíritu Santo es el amor confiado de Jesús que le reportaba la victoria sobre todos los poderes del mal y le atraía a todos los hombres a sí (Jn 12, 21ss; 16, 33). No sólo suscitaba su confianza, sino que también fundaba su seguridad. En efecto, el discípulo confiado se convierte en testigo fiel; apoyando su fidelidad en la de Dios, confía en que la gracia llevará a término su obra (Hch 20, 32; 2 Tes 3, 3ss; Flp 1, 6; 1 Cor 1, 7ss). Esta confianza que afirma el Apóstol incluso en las horas de crisis $(\mathrm{Gal} 4,10)$, le confiere una seguridad grande para anunciar con absoluta libertad la Palabra de Dios (1 Tes 2, 2; Hch 28, 31) ${ }^{14}$. Esto equivale a hablar abierta y libremente, con potencia de palabra y con valentía apostólica, a fin de predicar y dar testimonio ante las instancias hostiles.

12. Ibid.

13. Ibid

14. Cf. M. F. Lacan, Confianza, en X. Léon-Dufour, Vocabulario de teología bíblica, Barcelona 1982, 182. 
Significa también libertad filial para aproximarse a Dios con plena confianza, paciencia y franqueza, porque el nuevo sacerdocio de Cristo ha abierto el camino para entrar verdaderamente en el "santuario divino" (Heb 3, 6; 4, 14; 10, 19) $)^{15}$ y para ofrecer allí la densidad de la propia vida y los acontecimientos del mundo y de la Iglesia.

\section{LLEVAR A DIOS PARA ALCANZAR LA LIBERTAD VERDADERA}

El Espíritu Santo es expresión de la libertad de quien ama y se deja amar. Libertad fecunda, fuente de otras libertades. «El acompañamiento espiritual debe llevar más y más a Dios, en quien podemos alcanzar la verdadera libertad. Algunos se creen libres cuando caminan al margen de Dios, sin advertir que se quedan existencialmente huérfanos, desamparados, sin un hogar donde retornar siempre. Dejan de ser peregrinos y se convierten en errantes, que giran siempre en torno a sí mismos sin llegar a ninguna parte» ${ }^{16}$.

Es la libertad que tiene como paradigma al padre de los creyentes: Abrahán, el hombre de fe que sale como peregrino ${ }^{17}$. El recuerdo de la promesa, la Palabra de Dios es el único fundamento de la partida y del mismo caminar. Constancia y fidelidad. Fiarse de Dios, es la figura mayor de la fe. La obediencia del corazón a Dios que llama. Desde la inestabilidad del nómada que, al salir quema las naves y pone en "solo Dios» su punto de apoyo, sin ninguna seguridad. Abrahán camina hacia lo desconocido, siendo además ya anciano, sin descendencia, como extraño en tierra extraña. Sale, permanece desinstalado, está en la tierra pero sin poseerla, en una dinámica escatológica de "ya, pero todavía no», y de ruptura y superación con el pasado ${ }^{18}$. Es figura, paradigma de aquel que sabe que en este mundo y en esta sociedad está inerme, desnudo, sin rostro; confiando en una promesa; sabiendo que su vida es pobre, que las debilidades, miedos y tentaciones son muchas. Pero con la confianza puesta en el Dios de la libertad y del amor.

El Espíritu Santo es expresión de la libertad de quien ama y se deja amar, libertad fecunda, fuente de otras libertades y el coraje necesario

15. S. del Cura Elena, La sacramentalidad del sacerdote y su espiritualidad, en Comisión Episcopal del Clero, Espiritualidad sacerdotal, 119.

16. Francisco, Evangelii gaudium, 170.

17. Cf. Gn 12-24; G. Ravasi, Guía espiritual del Antiguo Testamento. El libro del Génesis (12-50), Barcelona-Madrid, 1994, 29-41; A. Fanuli, Abrahán, Jacob, Moisés y Josué, en A. Bonora (ed.), Espiritualidad del Antiguo Testamento, Sígueme, Salamanca 1994, 319-323.

18. Cf. G. Ravasi, Guía espiritual del Antiguo Testamento, 33. 
para «hacer» aquello que se «es» y viceversa. El ministerio supone vivir la libertad como llamada a trabajar por la justicia y la paz aquí y ahora. Son los «ámbitos de resonancia» del Espíritu-como indica Welker-, es decir, ese carácter público, intramundano de campos de fuerzas que es consecuencia de la acción del Espíritu ${ }^{19}$. Es el Espíritu de Jesús quien quiere penetrar con el presbítero en el futuro de Dios imaginándolo y construyéndolo en el primado de las Bienaventuranzas.

El acompañamiento espiritual es un proyecto de vida donde se deja de ser una persona «medrosa» para pasar a estar radicado en una relación de disponibilidad confiada en el Espíritu de Dios. El Espíritu, que es «relación», «encuentro», «acto creador»; es el acontecimiento siempre nuevo del amor entre el Padre y el Hijo, que hacen que se complementen en la diferencia y se «proyecten» en la fidelidad a su propia diferencia. De esta manera, crean comunión en la reciprocidad y en la tensión permanente hacia la libertad de "ser» que reconduce toda alteridad hacia la unidad, que ni rebaja ni confunde, sino que exalta y funde la diversidad de carismas y de personas. Pastores dabo vobis habla de no ser instrumentos inermes y pasivos, pues en cuanto "personas» se es "compañero de Dios» y «colaborador suyo»: «El sacerdote escogido por Cristo no como una cosa, sino como una persona, no es un instrumento inerte y pasivo, sino un 'instrumento vivo', como dice el Concilio, precisamente al hablar de la obligación de tender hacia la perfección. Y el mismo Concilio habla de los sacerdotes como 'compañeros y colaboradores' del Dios santo y santificador ${ }^{20}$.

El ministerio, a imagen del Padre y del Hijo por la acción del Espíritu, crea un presbítero que en la «caridad pastoral» se hace relación, encuentro, integración en el único proyecto del amor de Dios, que es libertad y coraje para «ser» $y$ «hacer» el proyecto del Reino en la Iglesia y en el mundo. Es unidad en la interacción de la «subjetividad» (que se expresa y hace) y las estructuras "crísticas» del mundo», lo cual conlleva una necesidad de discernimiento y que «se puedan encontrar los caminos de un genuino crecimiento, despertar el deseo del ideal cristiano, las ansias de responder plenamente al amor de Dios y el anhelo de desarrollar lo mejor que Dios ha sembrado en la propia vida» ${ }^{21}$.

19. Cf. M. Welker, Lo Spirito di Dio. Teologia dello Spirito Santo, Brescia 1995, 225-232. 20. Juan Pablo II, Pastores dabo vobis, 25.

21. Francisco, Evangelii gaudium, 171. 


\section{EL DISCERNIMIENTO COMO DOCILIDAD AL ESPÍRITU}

El acompañamiento espiritual supone la convicción de que el hombre que mediante la fe se ha convertido en discípulo del Reino, no puede dejar de discernir cada día el modo contingente mejor de mantenerse en la fidelidad a este don: "Siempre invita a querer curarse, a cargar la camilla, a abrazar la cruz, a dejarlo todo, a salir siempre de nuevo a anunciar el Evangelio» ${ }^{22}$.

El presbítero, hombre histórico, sometido al límite del tiempo y del espacio, no puede sustraerse a la elección y a la decisión, al menos implícita de entregarse a proyectar creativamente su existencia o adaptarse pasivamente a los cambios y las situaciones que la vida y el paso del tiempo llevan consigo. "La propia experiencia de dejarnos acompañar y curar, capaces de expresar con total sinceridad nuestra vida ante quien nos acompaña, nos enseña a ser pacientes y compasivos con los demás y nos capacita para encontrar las maneras de despertar su confianza, su apertura y su disposición para crecer» ${ }^{23}$.

¿De dónde nace esta necesidad de discernimiento en la Iglesia y en el mundo de hoy? Pablo, habla de discernimiento como centro y tarea de toda la vida cristiana, porque en lugar de la ley antigua, ahora poseemos el Espíritu que nos mueve a actuar como hijos (Gal 4, 4-6). Pero este Espíritu debe ser discernido de otros espíritus, a fin de ir descubriendo lo que agrada a Dios (Rm 12, 1-2; Ef 5, 8-10; Flp 1, 8-11; 1 Cor 11-13). Esto exige transformarse por la nueva mentalidad del Evangelio $(\operatorname{Rm} 12,2)$ y adquirir una cierta sensibilidad para los valores allí expuestos. Es necesaria la conversión al Espíritu del Señor (1 Cor 2, 14-16), que supone la subversión de los valores de este mundo por la locura de la cruz (1 Cor 1 , 20-21), y la predilección por los pequeños y los débiles (1 Cor 1, 27-29). Esta experiencia impulsa a captar y aceptar lo mejor en cada situación (Flp 1, 9-10; Ef 5, 15-17); y su criterio último son los mismos frutos del Espíritu: el amor, la alegría, el gozo, la paz, la amabilidad, la honestidad, la lealtad, la sencillez, el dominio de sí (Ef 5, 8-10; Flp 1, 9-11; Gal 5, 22-23); opuestos a los frutos de la carne (Gal 5, 19-21). Pues por sus frutos se conoce el buen espíritu (Mt 7, 16-20; 12, 33). El fruto del Espíritu por excelencia es, en última instancia, el amor fraterno, que es el carisma más alto $(1 \text { Cor } 12-13)^{24}$.

22. Ibid., 172.

23. Ibid.

24. Cf. M. Ruiz Jurado, El discernimiento espiritual, Madrid 1994, 7-9. 
San Juan en su primera carta resalta la fidelidad a Jesús encarnado, la comunión con los apóstoles y el amor fraterno como los signos del buen espíritu en el discernimiento (1 Jn 4, 3-8).

El discernimiento supone que el Espíritu guía hasta la verdad plena: «Os tendría que decir muchas cosas, pero ahora no las podríais soportar. Cuando venga el Espíritu de la verdad, él os guiará hacia la verdad plena» (Jn 16, 13). La revelación de Jesús es en sí misma definitiva y total: él ha manifestado todo lo que había oído al Padre. Pero la adecuada comprensión, la verdad completa de esta revelación ha de ser obra del Espíritu en cada nueva coyuntura de la Iglesia y en la situación existencial de cada creyente.

La Iglesia ha de mantenerse fiel a Jesús. Por eso, «el Paráclito, el Espíritu Santo que el Padre enviará en mi nombre os recordará todo lo que yo os he dicho» (Jn 14, 26), y os lo hará comprender. Con el mismo sentido: «El Espíritu de la verdad que procede del Padre y que yo os enviaré desde el Padre dará testimonio de mí» (Jn 15, 26). El Espíritu no es independiente de Jesús, ni añade nada a la experiencia de Jesús; nos actualiza su experiencia (nos la recuerda), nos ayuda a penetrar su sentido más profundo y nos hace ver cómo nos afecta en cada nueva situación. El Espíritu nos da una inteligencia de sus acciones no sólo en relación con la «interioridad», sino que nos da el sentido profundo de la «exterioridad».

El Espíritu sólo puede actualizar lo que ya Jesús había ofrecido: Jesús busca continuamente ser fiel al Padre, cumplir su voluntad. No se le da todo hecho, tiene que vigilar y orar, y los espíritus tampoco lo desconocen. Así pasa en el inicio mismo de su vida pública, que comienza siendo llevado al desierto para ser tentado (Mt 4, 1-11), y su decisión es crucial; marcará toda su vida. No es la gloria y el triunfo fácil, sino el anonadamiento. Por eso cuando quieren hacerlo rey $(\mathrm{Jn} 6,15)$ huye al monte a orar, afianza su fidelidad a la voluntad del Padre, donde el hombre se dimensiona a sí mismo en su relación con los demás, y en referencia a Dios. Hay que discernir los signos de los tiempos (Mt 16, 1-4), donde se entrecruzan la voluntad de los hombres (Pedro en su confesión-incomprensión del camino hacia Jerusalén) y el camino de entrega hasta el final. Es en la angustia y en la serenidad de Getsemaní (Mt 26, 36-46) donde Jesús vive la paz y la naturalidad de la súplica y acepta el designio del Padre.

El ministro ordenado ha de vivir alerta y disponible, porque el Espíritu no cesa de invitarlo a avanzar hacia el sentido verdadero de la historia de la salvación, con un discernimiento auténtico de la voluntad de $\operatorname{Dios}^{25}$, 
porque «parece que, a Dios, en su diálogo con el hombre, le gusta hablar históricamente, no atemporalmente. Y por lo tanto, las manifestaciones de Dios participan de la novedad y de la actualidad del acontecimiento histórico que vivimos» ${ }^{26}$. La paloma del Espíritu Santo se posa una y otra vez en lo terreno: conduce a la carne de Jesús, a su tierra que es la nuestra; dirige el discernimiento a lo que en la historia es la oportunidad «hic et nunc» que corresponde al camino de Jesús. El discernimiento no va solamente desde la subjetividad a la historia, sino también desde la historia a la subjetividad.

El discernimiento es ese conocimiento íntimo de la obra de Dios en el corazón del hombre y en la vida del mundo como don del Espíritu y fruto del amor: «El discernimiento es, pues, un acto que permite captar la voz de Dios entre todas las voces que nos llegan. Es una función profética, puesto que la profecía permite percibir y distinguir la presencia de Dios y su acción en el universo. Los profetas son los sismógrafos de la historia, capaces de registrar los más pequeños movimientos de Dios y transmitirlos a los que los desean percibir. Este papel profético permite remarcar la actividad actual de Dios o percibir aún las consecuencias de ciertas tareas humanas» ${ }^{27}$.

Existe la eterna tentación de ser ciegos y sordos en relación con la realidad general, con los signos de los tiempos, las expectativas de la gente, el sentido de la historia y el significado de la propia opción vocacional. Es el clásico producto de la sociedad y la cultura postmoderna: dejarse atrapar por lo efímero, las apariencias; gestionar los propios valores de la consagración y la misión con sentido consumista. Vivir el propio ministerio sin tensión creativa. No se sabe captar las provocaciones que flotan en el ambiente y parece que no se ve más que los propios intereses y no se preocupan de casi nadie ni de casi nada. Existe también la tentación de no tomar nunca decisiones concretas, no fiarse de la Palabra que infunde fuerza y coraje; no preguntarse por qué y por quién hay que hacer esto o aquello.

Es discernir desde la paradoja que supone la doble misión del Verbo y del Espíritu: luz-amor e historia-Espíritu. Esto supone, por tanto, que el Espíritu se objetiva categorialmente «en» y «a través» del Padre y del Hijo; él obra así en el nombre del Padre y del Hijo en la economía de la salvación. En el discernimiento la relación con el Espíritu no tiene el mismo orden de

26. P. J. Kolvenbach, Sobre el discernimiento apostólico en común, A.R. XIX (1986) 700. 27. F. Martin, Le discernement communautaire, Roma 1973, 293. 
relación que con el Padre y el Hijo, que son compañeros de nuestra fe. El Espíritu en el discernimiento es la profundidad de Dios Trino en el horizonte de la encarnación y la «allendeidad» del Verbo.

\section{EL ACOMPAÑAMIENTO ESPIRITUAL CAMINO EN GRACIA}

Para algún autor de nuestro tiempo, «la meta final de la dirección espiritual ha sido siempre el cultivo de la unión con Dios y, por tanto, ha estado vinculada a la relación del individuo con Dios» ${ }^{28}$. Al presbítero muy bien se le puede aplicar esta idea, pues es un hombre de Dios por ser un hombre de fe y oración, además de ser un hombre para los hombres, que comparte sus alegrías y dolores, angustias y esperanzas, que sabe escuchar, perder tiempo por los otros a fin de manifestar el verdadero rostro de Dios al hombre y el verdadero rostro del hombre a sí mismo; hombre de la verdad y del amor ${ }^{29}$ : «Este camino de autenticidad con uno mismo exige una cuidadosa atención de la propia interioridad, mediante la oración personal, la dirección espiritual, el contacto cotidiano con la Palabra de Dios, la lectura creyente de la vida sacerdotal, en unión con los otros presbíteros y con el obispo, y los instrumentos que sirven para crecer en las virtudes de la prudencia y del juicio» (Ratio 43).

El discernimiento supone para el presbítero comprometer la libertad humana con el absoluto de la voluntad divina, que confiere a cada una de las acciones realizadas un valor de eternidad. No es simplemente un telón de fondo de la espiritualidad del presbítero que da perspectiva al ministerio realizado en la historia, sino la inauguración de los últimos tiempos y la realización actual del juicio escatológico.

El arte del discernimiento sólo se aprende a través de la mediación de un hermano en la fe que conoce por experiencia personal este arte, aun en sus aspectos menos gratificantes y más laboriosos. En el proceso de discernimiento se precisa la mediación humana ${ }^{30}$ : «Cristo, el único Mediador, instituyó y mantiene en la tierra a su Iglesia, conducida por el Espíritu» ${ }^{31}$.

28. W. A. Barry - W. J. Connolly, La práctica de la dirección espiritual, 28.

29. Cf. T. Bertone, Il presbitero di fronte alle sfide del mondo attuale, en AA.VV., Sacerdoti per la nuova evangelizzazione. Studi sull'Esortazione apostolica "Pastores dabo vobis» di Giovanni Paolo II, Roma 1993, 25.

30. Sobre el tema existe una abundante bibliografía, desde todos los puntos de vista. En tiempos diferentes, hacemos notar tres obras de referencia que sitúa el estudio sobre el acompañamiento espiritual y da un elenco bibliográfico amplio y selecto. Cf. B. Jiménez Duque, La dirección espiritual, Barcelona 1962; L. M. Mendizábal, Dirección espiritual, Madrid 1978; E. Ancilli (ed.), Mistagogia e Direzione spirituale, Roma 1985.

31. Cf. Concilio Vaticano II, Lumen gentium, 8. 
Ahora bien, «el Espíritu sin la Iglesia sería una fuerza sin instrumento de acción. Una Iglesia sin Espíritu, sería un cuerpo sin alma» ${ }^{32}$. La Iglesia en su misterio de encarnación en el mundo supone la aceptación paradójica de su realidad. Realidad contradictoria de luces y sombras, de pecado y de gracia. Sólo desde la aceptación humilde de una Iglesia misterio de comunión y misión en la historia concreta se puede hacer el acompañamiento espiritual de discernimiento.

De nuevo, la doble misión del Verbo y del Espíritu se unen en una nueva dimensión que es la Iglesia: «La figura cristológica objetiva externa aporta y sustenta la presencia del Espíritu, y el Espíritu tiende a imprimir la figura de Cristo en todo ser viviente. La figura quiere hacerse vida y la vida busca una figura. Ambas cosas son aspectos inseparables y tan poco contradictorios como el Padre, el Hijo y el Espíritu Santo, e indican que la Iglesia como creación del Dios trino y uno se halla dentro de un amplio movimiento trinitario: es el pueblo de Dios Padre, creado por medio del Hijo en el Espíritu Santo, y que ostenta, en consecuencia, diversos rasgos que se complementan entre si $\rangle^{33}$.

En la Iglesia los creyentes en Cristo, guiados por el Espíritu, se ayudan mutuamente, trabajando juntos por la salvación de todos. Esta colaboración humana en la guía del Espíritu la llamamos «acompañamiento espiritual». Juan Pablo II la definía diciendo que «se trata de un medio clásico, que no ha perdido nada de su valor, no sólo para asegurar la formación espiritual, sino también para promover y mantener un continua fidelidad y generosidad en el ejercicio del ministerio sacerdotal. Como decía el cardenal Montini, futuro Pablo VI, «la dirección espiritual tiene una función hermosísima, y podría decirse que indispensable para la educación moral y espiritual de la juventud, que quiera interpretar y seguir con absoluta lealtad la vocación, sea cual fuese, de la propia vida; esta conserva siempre una importancia beneficiosa en todas las edades de la vida, cuando junto a la luz y a la caridad de un consejo piadoso y prudente, se busca la revisión de la propia rectitud y el aliento para el cumplimiento generoso de los propios deberes. Es medio pedagógico muy delicado, pero de grandísimo valor; es arte pedagógico y psicológico de grave responsabilidad en quien la ejerce; es ejercicio espiritual de humildad y de confianza en quien la recibe» ${ }^{34}$.

32. Cf. J. von Allmen, Spirito Santo, en Vocabulario bíblico, Roma 1969, 472-476.

33. G. Greshake, Ser sacerdote, Sígueme, Salamanca 1995, 101.

34. Juan Pablo II, Pastores dabo vobis, 81. 
El cuidado de la interioridad y la comunión, como indica la Ratio, son las exigencias que suponen que el presbítero «interiorice día tras día el espíritu evangélico por medio de una continua y personal relación de amistad con Cristo, hasta llegar a compartir sus sentimientos e imitar su comportamiento» (Ratio 41). Una cuidada serenidad de fondo, humana y espiritual que haga efectiva que es un «hombre de comunión, de misión y de diálogo, capaz de entregarse con generosidad y sacrificio a favor del pueblo de Dios, contemplando al Señor, que ofrece su vida por los demás» (Ratio 41).

Sólo se puede transformar la propia persona en un proceso donde se pueda objetivar la propia vida y ponerla en manos de Dios, para que él delinee un nuevo modo de ser en el Espíritu de Jesús. Es la necesidad de una confrontación dialéctica y a veces dolorosa, que confronta con el Evangelio y busca un nuevo rostro a través de una mediación, es decir, de una cierta coparticipación de la vida y de la fe con otro creyente. Es compartir el «pan y la palabra» con la vida en la propia Iglesia.

\section{EL ARTE DEL ENCUENTRO ESPIRITUAL}

El acompañamiento, por tanto, exige docilidad al Espíritu, diálogo y nueva alianza como espacios donde el ministerio se hace camino de crecimiento y experiencia del don recibido en la comunión de la «fraternidad sacramental» del presbítero: «El espíritu de comunión se funda en el hecho de que la Iglesia, en cuanto pueblo convocado por Cristo, está llamada a vivir, como lo ha hecho desde sus orígenes, una fuerte experiencia de vida comunitaria. Conviene considerar que, recibido el orden del presbiterado, los sacerdotes 'están unidos todos entre sí por la íntima fraternidad sacramental y forman un presbiterio especial en la diócesis a cuyo servicio se consagran bajo el obispo propio' (PO 8). En virtud de la propia ordenación, el presbítero forma parte de una familia, en la cual el obispo es el padre» (Ratio 51).

San Pablo nos dice que «cuantos se dejan llevar del Espíritu de Dios son hijos de Dios» $(R m 8,14)$. Esta es la confianza del presbítero, una confianza hecha de profundidad y de amor en la realización del proyecto del Espíritu donado en la imposición de manos. La economía del Nuevo Testamento introduce al presbítero a servir al Padre en espíritu y en verdad por una comunicación íntima con él en el Espíritu Santo ${ }^{35}$. El Dios que sale al

35. Cf. L. M. Mendizábal, Dirección espiritual, 15-16. 
encuentro del hombre, es el Dios Padre que dialoga en lo profundo del ser desde una llamada total y radical. Pastores dabo vobis, cuando nos habla de la vocación, afirma que es la llamada que el Padre, "amor increado y creador», hace al creyente desde la irradiación de su amor: «La formación sacerdotal es un camino de transformación, que renueva el corazón y la mente de la persona, para que pueda discernir cuál es la voluntad de Dios: lo que es bueno, lo que le agrada, lo perfecto $(\mathrm{Rm} 12,12)$. El gradual crecimiento interior en el proceso formativo debe tender principalmente a hacer del futuro presbítero el hombre del discernimiento, capaz de interpretar la realidad de la vida humana a la luz del Espíritu, y así escoger, decidir y actuar conforme a la voluntad divina» (Ratio 43).

Es el diálogo entre Dios y el hombre, entre el amor de Dios y la libertad de un ser humano que responde al amor en el amor. El Padre es pura gratuidad, el que ama porque sí, sin más motivo que el «amor-en-sí», sin más pretensión que el bien del otro, sin esperar nada a cambio, y sin más gratificación que la alegría de $a_{m a r}^{36}$. Esta es la intimidad fundamental, esa que comenzó con el inicio del diálogo de Dios con el candidato al sacerdocio y que no concluirá nunca por la gracia del Espíritu Santo, porque «la vocación es un don de la gracia divina» ${ }^{37}$. En este contexto, "los seminaristas serán acompañados para identificar y corregir la mundanidad espiritual: la obsesión por la apariencia, una presuntuosa seguridad doctrinal o disciplinar, el narcisismo y el autoritarismo, la pretensión de imponerse, el cultivo meramente exterior y ostentoso de la acción litúrgica, la vanagloria, el individualismo, la incapacidad de escucha de los demás y todo tipo de carrerismo» (Ratio 42).

En este contexto de diálogo con Dios, el Espíritu dirige la historia de la salvación. El «hombre nuevo», renovado en el Espíritu, escribe su propia página en la historia de la salvación guiado por el Espíritu ${ }^{38}$ "hasta que todos alcancemos la unidad de la fe y del conocimiento del Hijo de Dios y seamos hombres cabales y alcancemos la madurez cristiana» $(\mathrm{Ef} 4,13)^{39}$. Es vivir la experiencia de Jesús que dice: «Venid y ved». Experiencia de ver, escuchar, convivir y compartir el pan y el trabajo, la doctrina y las confidencias, los aplausos, las críticas... Es experiencia invasora, posesiva de Jesús, «mi Señor» $(F I p ~ 3,8)$ por quién son agarrados, alcanzados,

36. Juan Pablo II, Pastores dabo vobis, 36.

37. Ibid., 36.

38. Concilio Vaticano II, Gaudium et spes, 19.

39. Cf. A. Crespo Hidalgo, El acompañamiento espiritual, en Comisión Episcopal del Clero, Espiritualidad sacerdotal, 530 . 
reducidos, ganados (Flp 3, 12), que produce en los seguidores una transformación vital profunda, una nueva criatura y una persona nueva nacida de esta experiencia: «Vivo, pero no yo, sino que es Cristo quien vive en mí» (Gal 2, 10). Es dejarse acompañar por Jesús. «Estar con él» es algo esencial para los Doce, para captar la identidad de Jesús y los secretos del Reino y hacerse dóciles a su Espíritu ${ }^{40}$. Esto exige docilidad, dejarse educar en el camino de la fe: «Sean [los seminaristas] educados para la simplicidad, la sobriedad, el diálogo sereno, la autenticidad y, como discípulos en la escuela del Maestro, aprendan a vivir y actuar desde la caridad pastoral que corresponde, a ser siervos de Cristo y administradores de los misterios de Dios (1 Cor 4, 1)» (Ratio 42).

\section{EL ARTE DE CUIDAR ENTRE TODOS}

El arte de cuidar entre todos se realiza en "la casa y la escuela de la comunión... el presbítero debe ser el hombre de la comunión... La comunidad del Seminario es una familia, caracterizada por un clima grupal que favorece la amistad y la fraternidad» (Ratio 52).

Ser acompañados en el camino espiritual es la experiencia de ser orientados, sostenidos, ayudados, purificados y liberados en el corazón e iluminados en el propio itinerario: «Necesitamos de hombres y mujeres que, desde su experiencia de acompañamiento, conozcan los procesos donde campea la prudencia, la capacidad de comprensión, el arte de esperar, la docilidad al Espíritu, para cuidar entre todos a las ovejas que se nos confían de los lobos que intentan disgregar el rebaño» ${ }^{41}$.

La identidad y la espiritualidad propias del presbítero serán las que marquen lo específico del acompañamiento, requiriendo conocimiento tanto intelectual como afectivo de la dinámica y de la vida del presbítero que, configurado «con Cristo Cabeza y Pastor, Siervo y Esposo de la Iglesia» ${ }^{42}$, encuentra la fuente de su espiritualidad específica. El resultado es la nueva alianza que instaura el Espíritu Santo en la globalidad de la vida. La imagen de esta alianza es precisamente Moisés ${ }^{43}$. Por esta razón la espiritualidad propia ha de estar radicada en las actitudes que el sacerdote es ontológicamente.

40. Cf. P. Arrupe, Estar y trabajar con Jesús. Sacerdotes hoy, Sal Terrae 66 (1978) 3-13.

41. Francisco, Evangelii gaudium, 171.

42. Juan Pablo II, Pastores dabo vobis, 2.

43. Cf. A. Fanuli, Abrahán, Jacob, Moisés y Josué, 326-331; G. Auzou, De la servidumbre al servicio. Estudio del libro del Éxodo, Madrid 1974, 81-106. 
Moisés es el paso de la promesa al pacto histórico, al comienzo de la historia del pueblo de Israel antiguo y nuevo ${ }^{44}$. Moisés y los acontecimientos de la entrada en la tierra son los protagonistas. La historia es narrada como riesgo y aventura. La aventura de recorrer el propio camino interior. Moisés desde el nacimiento siente su vida ya amenazada, su exilio, su resolución de volver (como quien ve lo invisible), actúa movido por una fuerza (la fe en Dios) que no se detecta visiblemente. El Espíritu que actúa en lo escondido de la vida, ahí agazapado indicando el camino interior, construyendo rutas y nuevos itinerarios. La pascua y el episodio del mar... Por la oración el riesgo y la huida, la persecución y la entrada en el mar, que simboliza lo caótico e inseguro, reino del mal... La guía de Moisés por el desierto, lugar de combate y perdición, la tentación a Dios, la rebeldía. Moisés aprende a orar, se humilla, objeta y sobre todo pide y, en respuesta a su petición el Señor le confía su Nombre inefable que se revelará en sus grandes gestas. Dios habla con Moisés cara a cara, como habla un hombre con su amigo. Conversa con Dios, le escucha en la montaña y le implora. La vida se convierte en parresía, audacia, valentía ante la muerte: milagros, victorias ejemplares, prodigios extraordinarios y, sobre todo, modelos de sufrimiento para mostrar la resistencia, la constancia y el combate.

El Espíritu incide en la historia dramática de los hombres y funda a la vez esa misma historia, la construye, la hace progresar, es una fuerza histórica de avance hacia el Reino de Dios. Por el Espíritu el presbítero escucha la Palabra de Dios en cada momento de su vida, la discierne y en compañía de otro «hermano» busca la respuesta. Busca la respuesta para su pueblo y muestra caminos de encuentro y de diálogo. El acompañado en el camino del seguimiento se hace compañero y acompañante del pueblo de Dios. Se adhiere al designio del Padre y del Hijo. Vivir en el Espíritu es conocer el sentido de Dios y de su intervención a favor de los suyos. Discernirla es su tarea. Es un compromiso con el designio de Dios. Fuerza vital, recurso de constancia, prueba de fidelidad a lo comprometido. Es inventar futuro, no dejarse agarrar por la seguridad y el miedo. El Espíritu compañero del camino se convierte así en el lugar de la decisión,

44. «Moisés pertenece a aquella categoría de personas que hacen la historia religiosa de un pueblo, en el sentido de que se sitúan al comienzo de un movimiento, de la concepción de la vida o de la praxis religiosa, a partir de la cual marcarán la existencia futura de un pueblo o de continentes enteros. El judaísmo con su fe en Yahvé -el Dios de los «padres», del desierto y de toda la historia de Israel, el Dios creador y el Dios de las exigencias éticas, el Dios que los cristianos llamarán 'el Padre de nuestro Señor Jesucristo' (2 Cor 1, 3)- es obra de Moisés» (A. Fanuli, Abrahán, Jacob, Moisés y Josué, 326). 
de la verdad, del encuentro y de la alianza de amor que Dios hace con el presbítero. El Espíritu, como un pedagogo, toma al presbítero donde está y progresivamente lo conduce al Padre y al Hijo para la misión: «El auténtico acompañamiento espiritual siempre se inicia y se lleva adelante en el ámbito del servicio a la misión evangelizadora. La relación de Pablo con Timoteo y Tito es ejemplo de este acompañamiento y formación en medio de la acción apostólica. Al mismo tiempo que les confía la misión de quedarse en cada ciudad para 'terminar de organizarlo todo' (Tit 1, 5; cf. 1 Tim 1, 3-5), les da los criterios para la vida personal y para la acción pastoral $»^{45}$. Así, desde esta perspectiva el discernimiento y la experiencia de acompañamiento espiritual suponen para el presbítero el esfuerzo de «ser formado de modo que su corazón y su vida sean conformes al Señor Jesús, llegando a ser un signo del amor de Dios para cada hombre. Íntimamente unido a Cristo, podrá anunciar el Evangelio y llegar a Ser instrumento de la misericordia de Dios; conducir y corregir; interceder y cuidar la vida espiritual de los fieles a él confiados; escuchar y acoger, respondiendo también a las exigencias y a los interrogantes profundos de nuestro tiempo» (Ratio 40). 